\title{
ANÁLISE DA MATURIDADE DO PROCESSO DE DESENVOLVIMENTO DE PRODUTOS ASSOCIADOS A INDÚSTRIA 4.0 NO MERCADO CAPIXABA ATRAVÉS DE PESQUISA APLICADA
}

\author{
ANALYSIS OF THE MATURITY OF THE DEVELOPMENT PROCESS OF PRODUCTS \\ ASSOCIATED WITH INDUSTRY 4.O IN THE CAPIXABA MARKET THROUGH APPLIED \\ RESEARCH
}

\author{
$\underline{\text { Flavio Lucio Santos de Carvalho }}^{{ }^{1 *} \&} \underline{\text { Juliana Loureiro Ferreira }}^{2}$ \\ 12 Centro Universitário Salesiano - Unisales. \\ 1* fcarvalho@salesiano.br ${ }^{2}$ juliana.lofe23@gmail.com
}

\section{ARTIGO INFO.}

\section{Recebido em: 21.10.2021}

Aprovado em: 20.12.2021

Disponibilizado em: 31.01.2022

\section{Palavras-Chave:}

Eficiência; Industria, PDP; Engenheiro de Produção; Ferramentas da Qualidade; Pilares Tecnológicos.

\section{KEYWORDS:}

Efficiency; Industry; PDP; Production Engineer; Quality Tools; Technological Pillars.

*Autor Correspondente: Carvalho, F. L. S., de.

\section{RESUMO}

$\mathrm{O}$ presente artigo teve como objetivo mensurar a maturidade do processo de desenvolvimento de produtos (PDP) no setor industrial do estado do Espírito Santo relacionando-o com a indústria 4.0, ou seja, verificar qual o conhecimento e aplicação das empresas capixabas no que tange o processo de desenvolvimento do produto, a aplicação dos conceitos de indústria 4.0 e como utilizam tais processos como uma vantagem competitiva para alavancagem de resultados, se destacando na Indústria capixaba, as empresas que tem como pilares a eficiência da produção e com abordagem PDP para se estabelecer no mercado. Logo, a forma com que as empresas encontram meios para alcançar tal objetivo, é o foco no processo de desenvolvimento do produto, que "se bem gerenciado pode contribuir decisivamente para a competitividade das empresas nesse ambiente" (JUGEND, 2006). Para sequenciar o projeto foram considerados três pilares do PDP: a eficiência da produção, o lead time e a flexibilidade da linha de montagem. Para isto, foi realizado uma triagem nas empresas com sede no Espírito Santo e foram avaliadas somente as que possui algum processo de desenvolvimento de produto. Neste sentido, tratou-se de analisar o posicionamento dessas empresas, demonstrar soluções e melhorias para o desenvolvimento de produto e a necessidade de um programa de aperfeiçoamento do processo de produtos. $\mathrm{O}$ resultado obtido foi a constatação da imaturidade do mercado quanto PDP e que o papel dos engenheiros de produção no desenvolvimento de produtos capixabas é pequeno se comparado aos demais profissionais que atuam no segmento de PDP e as empresas não utilizam todas as ferramentas de qualidade para o PDP.

\section{ABSTRACT}

This article aimed to measure the maturity of the product development process (PDP) in the industrial sector of the state of Espirito Santo, relating it to industry 4.0, that is, to verify the knowledge and application of companies in Espirito Santo regarding the product development process, the application of industry 4.0 concepts and how they use such processes as a competitive advantage to leverage results, standing out in the Espírito Santo Industry, companies that have production efficiency as pillars and with a PDP approach to establish themselves in the market. Therefore, the way in which companies find ways to achieve this goal is the focus on the product development process, which "if well managed can decisively contribute to the competitiveness of companies in this environment" (JUGEND, 2006). To sequence the project, three pillars of the PDP were considered: production efficiency, lead time and assembly line flexibility. For this, a screening was carried out in companies headquartered in Espírito Santo and only those with a product development process were evaluated. In this sense, the aim was to analyze the positioning of these companies, demonstrate solutions and improvements for product development and the need for a program to improve the product process. The result obtained was the verification of the immaturity of the market regarding PDP and that the role of production engineers in the development of Espirito Santo products is small compared to other professionals working in the PDP segment and companies do not use all the quality tools for the PDP. 


\section{INTRODUÇÃO}

Na indústria capixaba cerca de $90 \%$ das empresas efetuam desenvolvimento de novos produtos ou inovações tecnológicas com recursos próprios, e considerando que muitas não possuem recursos disponíveis, este mercado pode ser explorado largamente no estado, como forma de melhorar o desempenho no setor econômico. Em tempo, na atual situação econômica onde há uma alta competitividade para uma empresa apresentar resultados positivos, ela precisa ganhar destaque.

O mercado tem demonstrado uma evolução em sua economia, com crescimento no PIB de $+3,0 \%$ ao ano (IJSN, 2019). Tal fato está relacionado a recuperação da economia visto que em todas as tratativas ao desempenho consideradas o resultado foi superior ao último trimestre de 2018.

Ainda, a indústria 4.0 desencadeada através da quarta revolução industrial, traz consigo a produção baseada em sistemas cyber-físicos, impulsionando avanços no processo produtivo, com aspecto elaborado em relação ao uso da tecnologia, aumentando consideravelmente o ideal de automatização, diferente do patamar em que a indústria está habituada. Em tempo, a internet das coisas (IOT), como é chamada a indústria 4.0, se relaciona intimamente com outros requisitos, tais como como conectividade, big data, inteligência artificial e dentre outros. A indústria 4.0 transforma a maneira em que as máquinas se comunicarão e utilizarão as informações para otimizar o processo produtivo, angariando autonomia, economia e agilidade (Magrini, 2018).

No processo evolutivo das indústrias capixabas é preciso identificar o nível tecnológico no qual se encontram ao comparar a revolução da indústria 4.0 e se sua maturação está proporcionalmente atrelada ao PIB capixaba. Ainda, elucidar os principais pilares para essas empresas se manterem competitivas no mercado e se a abordagem PDP tem papel fundamental para definir o sucesso do novo produto.

Portanto, o seguinte artigo tem como objetivo mensurar a maturidade do processo de desenvolvimento de produtos (PDP) no setor industrial do estado do Espírito Santo relacionando-o com a indústria 4.0, ou seja, verificar qual o conhecimento e aplicação das empresas capixabas no que tange o processo de desenvolvimento do produto, a aplicação dos conceitos de indústria 4.0 e como utilizam tais processos como uma vantagem competitiva para alavancagem de resultados, se destacando na Indústria capixaba, as empresas que tem como pilares a eficiência da produção e com abordagem PDP para se estabelecer no mercado.

\section{REFERENCIAL TEÓRICO}

\subsection{PROCESSO EVOLUTIVO DA INDÚSTRIA}

Inicialmente, os humanos faziam uso da força de escravos e animais para realizar certas tarefas, temos como exemplo a grande arquitetura egípcia. O processo logístico originou-se exigindo muito esforço físico, com atividades repetitivas e manuais, mas com a chegada da tecnologia, de acordo com a época, essas atividades foram distribuídas aos recursos, como grandes animais e até mesmo as forças naturais, como ventanias e a força da água. Com o passar do tempo, o 
segmento industrial vem se adaptando à tecnologia dominante da época, sendo possível estruturar seu estágio de desenvolvimento, conforme a Figura 1.

Figura 1.Linha do Tempo das Revoluções Industriais

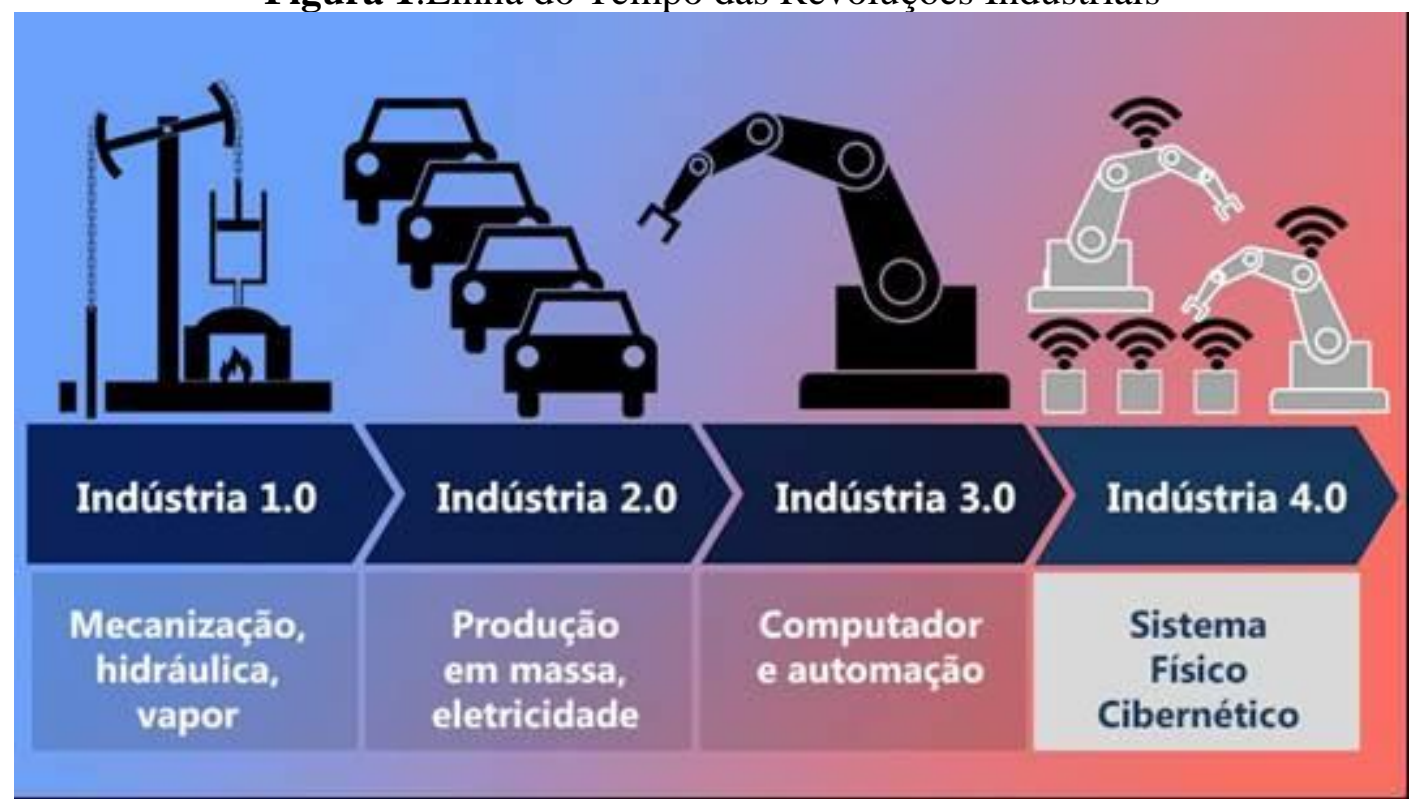

Fonte: ccaexpress.com.br (2019).

Na primeira revolução industrial, denominada indústria 1.0, ocorreu no século XVIII, onde a energia gerada através do vapor deu início à fase de mecanização de uma série de linhas de produção, resultando no aumento da capacidade produtiva e produzindo modelos industriais por muitos anos (Slack et al., 2002).

Em meados do século XIX e o avanço nas linhas de produção com a eletricidade, iniciou-se a segunda revolução industrial. A partir disso, Henry Ford adaptou esses princípios à produção e montagem de automóveis, ou seja, a partir desta revolução os veículos eram montados e/ou produzidos em etapas na correia transportadora (Sacomano \& Sátyro, 2018).

Já no século XX, o setor industrial recebeu algumas evoluções com o auxílio da automação parcial, tais como os controles, antes mecânicos e que nesta fase se tornaram elétricos. Para essa migração foram utilizados computadores e softwares (Sacomano \& Sátyro, 2018).

Com o aprimoramento da tecnologia da informação e redes a interação entre o homem e a máquina tiveram um grande avanço. Tal interação possibilitou a exibição de resultados, adaptação de processos com a manufatura enxuta, reduzindo desperdícios, estoques, com maior participação dos clientes e produzindo o necessário, conforme filosofia JIT (Just in Time - Na hora certa) (Leone, 2007).

Visando a melhora no tempo de produção, confiabilidade no trabalho a ser executado e, principalmente, qualidade, foi introduzido a robótica automatizada junto aos Servomotores ${ }^{1} \mathrm{e}$ softwares.

1 Servomotores são atuadores originalmente criados para controlar movimentos com posicionamentos de alta precisão, reversões e alto desempenho

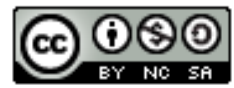




\subsection{INDÚSTRIA 4.0}

Com o aprimoramento da internet, no século XX o mundo se vê diante a metamorfose digital e a indústria passou a monitorar virtualmente dialogando com o banco de dados (big data) e com as mídias sociais, no que se refere a máquinas, smartphones, tablets e acesso remoto à internet. Neste contexto, o mercado prepara-se para a entrada, cada vez mais prematura, de consumidores, a cada dia mais exigentes sobre o mercado e sua postura competitiva e inovadora, por isso, traçam estratégias de marketing e criam empresas e/ou soluções de negócios inovadoras, resultando na ameaça de empresas tradicionais.

Plattform Industrie 4.0 (Plataforma Indústria 4.0), lançado em 2011 em Hannover, na Alemanha, parte do pressuposto que a remodelação da essência da produtividade nas indústrias atuais e mantê-las entre as mais competitivas do mundo é uma melhor definição de indústria 4.0, pois a partir deste novo modelo define-se como a priore uma visão de negócios voltada para a transformação tecnológica (Teles, 2018)

Segundo os autores Skilton e Hovsepian (2018), a revolução 4.0 decorreu através das inúmeras diferenças e possíveis combinações entre as tecnologias integradas à Internet. Por isso, é considerada uma das revoluções mais importantes, já que favorece a integração de toda cadeia produtiva, aumentando a competitividade, qualidade, perspectiva de negócio, confiabilidade e a comunicação entre empresas e clientes.

Foi a partir destes passos iniciais que algumas indústrias na Europa começaram a compreender os benefícios e as vantagens competitivas da implementação da indústria 4.0 como uma inovação, criando assim cenários para a produção e futuro económico de processos e gestão industrial.

\subsection{PRINCÍPIOS DA INDÚSTRIA 4.0}

De acordo com Silveira (2017), onde este destaca que foram criados seis princípios para a adequação empresarial aos novos sistemas produtivos existentes, cuja finalidade é a obtenção do sucesso na implantação da indústria 4.0 (Quadro 1).

Quadro 1. Os Seis Princípios para adequação empresarial

\begin{tabular}{|c|c|}
\hline Principio & Descrição \\
\hline Operação em tempo real & $\begin{array}{l}\text { Este princípio enfatiza que a organização deve possuir processamento, troca de } \\
\text { informações e tomadas de decisões em tempo real. }\end{array}$ \\
\hline Gêmeo Digital & $\begin{array}{c}\text { Rege a necessidade de criar um ambiente propício para que sejam feitas } \\
\text { simulações para identificação de erros remotamente e sugestões de melhoria } \\
\text { quando pertinente, sem impactos na operação física. }\end{array}$ \\
\hline Rastreabilidade & $\begin{array}{c}\text { Com apoio de sensores alocados em posições estratégicas ao objetivo fim para } \\
\text { garantir o monitoramento remotos dos processos executados }\end{array}$ \\
\hline Adaptabilidade & $\begin{array}{l}\text { Através do cyber-físico ocorre a integração entre o sistema de produção e as } \\
\text { tomadas de decisões através de pontos de melhoria que podem surgir nos ciclos, } \\
\text { utilizando as informações disponíveis instantaneamente }\end{array}$ \\
\hline $\begin{array}{l}\text { Direcionamento aos } \\
\text { serviços }\end{array}$ & $\begin{array}{l}\text { Utilizando a IOT (internet das coisas) como base para arquitetura de softwares } \\
\text { específicos ao serviço com a finalidade de reorganizar departamentos de } \\
\text { tecnologia da informação, melhorando o relacionamento entre setores ligadas ao } \\
\text { suporte tecnológico }\end{array}$ \\
\hline Modularidade & $\begin{array}{l}\text { Possibilidade de alternância entre tarefas sem qualquer impacto quando } \\
\text { necessário }\end{array}$ \\
\hline
\end{tabular}

Fonte: Autores (2021). 


\subsection{ADVENTOS DA INDÚSTRIA 4.0}

A tecnologia adicionada a este novo modelo é baseada em onze pilares tecnológicos (Figura 2), que podem ser utilizadas combinadas entre si, promovendo resultados mais expressivos e decisivos para a organização (Skilton \& Hovsepian, 2018).

Figura 2. Pilares tecnológicos da Indústria 4.0

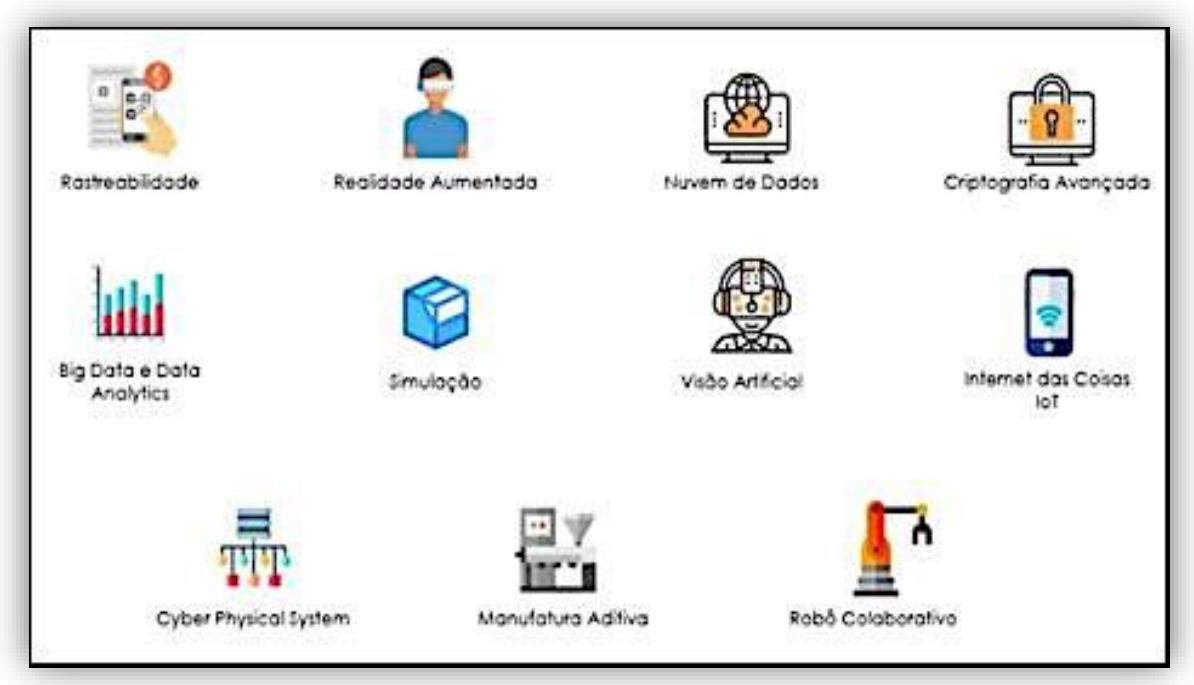

Fonte: (Teles, 2017)

\subsubsection{Rastreabilidade}

No tocante da quarta revolução industrial, a rastreabilidade está voltada para o posicionamento de produtos e dados de qualitativos. Por isso, dispositivos digitais, estrategicamente posicionados, são necessários para monitorar todo o ciclo, desde a fabricação da matéria prima até a entrega ao cliente, gerando estatísticas sobre os custos e tempo de produção em qualquer etapa do processo (QS Consultoria, 2017).

A estratégia de rastreabilidade se deu pela demanda de mercado em manter o controle efetivo de toda cadeia produtiva, refletida também pela alta competitividade, crescente exigência quanto à qualidade e confiabilidade. $\mathrm{O}$ investimento na rastreabilidade traz como benefício a vantagem competitiva e segurança, já que o rastreio manual possui maior tempo de resposta e é passivo de erros.

Um modelo de rastreabilidade amplamente conhecido, principalmente após a pandemia de COVID 19 é a leitura e pagamento via $Q R C o d e$, onde o contato físico está sendo combatido como forma de prevenção.

\subsubsection{Realidade aumentada}

A aplicação do RA (Realidade Aumentada) é a integração de elementos ou informações virtuais com elementos reais através de uma câmera, podendo reduzir tempo de retorno a defeitos de fabricação, elevando o nível de confiabilidade sem precedentes e consequentemente aumentando a qualidade. A simulação de cenários virtuais sobre o físico permite a integração de dados em tempo real com sistemas industriais, GPS, câmeras e internet. Essa integração

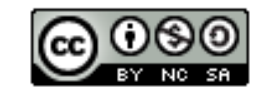


permite a avaliação do processo produtivo em todas as fases, viabilizando decisões assertivas acerca do custo final, inclusive elevar a coparticipação dos clientes na produção, corrigindo erros latentes a qualidade do produto e/ou personalização (Winter, 2020).

$\mathrm{Na}$ indústria, se faz possível a operação remota de máquinas de grande porte e riscos, acompanhamento em tempo real e remoto da produção e a orientação de manutenção e segurança no ambiente fabril. Para este setor pode-se considerar um enorme avanço, visto que a redução dos riscos aos trabalhadores, incremento na capacidade de produção e otimização de recursos são potenciais neste pilar.

\subsubsection{Nuvem de dados e Criptografia aumentada}

A nuvem de dados possibilita o acesso remoto de dados, arquivos e simulações da organização, através de uma conexão de internet. (COBBOS, 2018). De forma remota, é possível corrigir qualquer falha, intempérie e realizar consultas em tempo real, garantindo total acessibilidade e tomada de decisões. A indústria 4.0 propõe que o desempenho seja aumentado e otimizado visto o aumento na capacidade e velocidade de processamento. $\mathrm{O}$ uso dos recursos de nuvem garante às empresas a virtualização, gerando maior mobilidade, segurança aos processos e agilidade no armazenamento de dados.

Considerando que os dados gerados e armazenados em nuvem podem conter arquivos confidenciais e acessos a qualquer processo, linhas de produção e acessos remotos, é necessário que as empresas invistam na criptografia, uma vez que essa segurança será atualizada diariamente afim de evitar roubo de informações ou acessos em máquinas e/ou arquivos por pessoas não autorizadas.

\subsubsection{Big Data e Analytics}

O Big Data tornou-se um forte alicerce a todas as tecnologias, devido sua alta capacidade de processamento de dados. Para o eixo industrial, o processamento é através da pré definição de algoritmos que possuem capacidade de aprendizagem, e após analisar o processo, acessam a nuvem e define mudanças ou melhorias necessárias aquele processo. Essa autonomia eleva a análise de falhas, garantindo a qualidade. Ainda, a tecnologia Big Data e Analytics aperfeiçoa a qualidade da produção seriada, economizando energias que antes eram desperdiçadas e melhora consideravelmente a performance dos equipamentos.

\subsubsection{Simulação}

Conceito criado para representar de forma digital um objeto ou processo já existente no físico. Também conhecido como "gêmeo digital", foi utilizado pela primeira vez pelo Professor Michael Grives da Universidade de Michigan em 2003 em um cenário de negócios. (Moura \& Nascimento, 2018).

Para uma simulação real, é necessário criar o gêmeo digital utilizando softwares voltados para o cenário a ser recriado e aplicar a uma linha de produção (Figura 3). A partir disso será possível analisar os possíveis erros e suas causas, simular uma melhoria e visualizar os resultados geradas através delas, sem impactar a operação real. Essa simulação gera dados robustos e análises prévias para estudo viabilizando futuras tomadas de decisões pertinentes a operação.

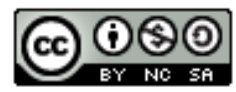



Especial "Ciência na Prática", 01-21.

Figura 3. Simulador de Processos

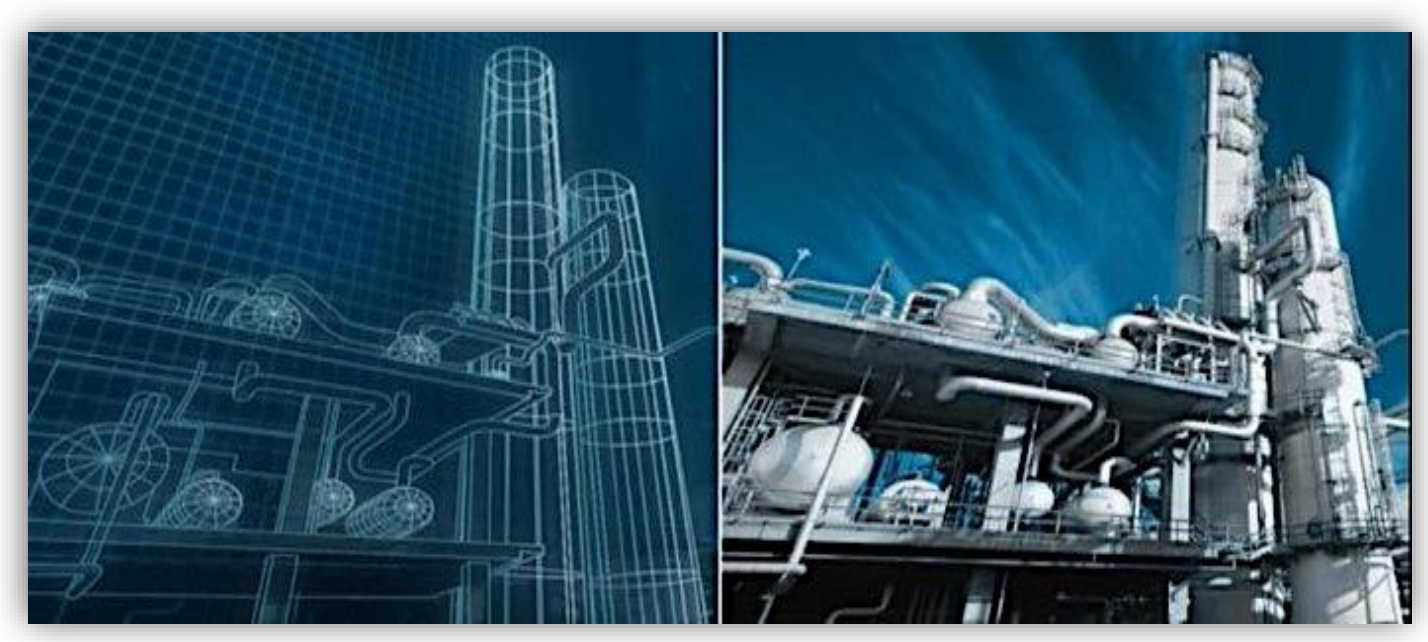

Fonte: Industria 4.0, 2020

A simulação diminui a frequência de erros, reduz custos e permite a pluralidade ao processo sem ônus, pois a visibilidade no interior da simulação é comum a todos os setores, deste a mecânica ao dressing.

\subsubsection{Visão Artificial}

Este pilar é uma das inovações que fazem uso de câmeras na linha de produção e pode ser combinada a, pelo menos, dois outros pilares da indústria 4.0, sendo eles a rastreabilidade e a R.A. Antigamente, as câmeras na indústria eram somente para segurança comportamental e patrimonial, entretanto com a tecnologia potencial, já é possível processar dados, acessar softwares e integração com rede de ethernet ou profibus (RTI Automação, 2018).

Um dos ganhos levados em consideração no momento do planejamento é que a visão artificial possui abrangência total a cadeia produtiva, eliminando o antigo processo de auditoria por amostragem realizado, em sua maioria, por pessoas em um processo repetitivo, gerando um volume de erros considerável. Importante considerar que a Visão Artificial pode trazer ganhos e autonomia para a indústria, desde que conectada a um banco de dados e a uma rede de comunicações IOT, podendo tomar decisões em tempo real.

\subsubsection{Internet das Coisas (IOT)}

Principal tendência para a propagação da quarta revolução industrial, hoje o IOT (Internet das Coisas) promove a maior parte da automação dentro das indústrias. No IOT os equipamentos, ditos coisas, que executam a transmissão de informações e também as recebe (Magrini, 2018).

Deste modo, toda transmissão dos dados coletados de forma instantânea pode ser via Wireless para outro hardware e processador responsável por ajustar melhorias em dado processo. Assim como as demais tecnologias, o IOT permite aos gestores o acompanhamento dos processos de maneira profunda, avaliando desempenho de cada etapa em tempo real, através de sensores, recursos de comunicação e sistemas.

\section{@ (ब)}




\subsubsection{Cyber-Physical Systems (CPS)}

Este pilar é o produto da integração entre a comunicação, controle e a computação, através da rede de dados e processos, ou seja, através desses recursos a indústria consegue representar o ambiente físico no virtual, promovendo a simulação e a tomada de decisão sem impactos reais. O CPS são sistemas de processamento individual e seus elementos Seu funcionamento permeia a alta capacidade de processamento de dados recebidos através dos sensores e, consequentemente, transmissão dos dados em forma de comando para os atuadores. Com base nos dados de retorno dos sensores, sua programação pondera as possíveis alternativas e atualizam essas informações em tempo real para os comandos estarem o mais preciso possível. Ainda, o CPS está conectado a central big-data que o atualiza das informações pertinentes e que funciona como um banco de dados, permitindo a análise e a comparação dos resultados com o banco de dados.

Importante frisar que o gerenciamento destes recursos se faz imprescindível para seu perfeito funcionamento e a inciativa privada vem se adequando com o passar dos anos. Com a existência de redes de integração de dados, as empresas da indústria 4.0 nunca estarão isoladas.

\subsubsection{Manufatura Aditiva}

Também chamada de Impressão 3D, hoje possui utilização na produção de protótipos físicos. $\mathrm{Na}$ indústria 4.0, ela é utilizada em grande escala para a produção de menores lotes de peças personalizadas, diminuindo altos custos de personalização e fabricação (Figura 5).

No processo de impressão 3D, as camadas de material são sobrepostas, concebendo o objeto modelado em um software dedicado, onde são elaborados o desenho e a escolha do tipo de material a ser utilizado na fabricação. Fazer uso da manufatura aditiva pode trazer inúmeros benefícios para as organizações, tais como velocidade de produção, baixo custo de produção unitária, liberdade de design e com níveis de complexidade elevado, alta customização e sustentabilidade. se comunicam e coordenam os sensores e atuadores, físicos e virtuais em que são executados. Seu objetivo é controlar o ambiente e para que seja possível, fazem uso de sensores dispostos ao longo de todo ambiente a ser controlado, para uma tomada de decisão mais assertiva (Figura 4).

Figura 4. Modelo cyber-físico

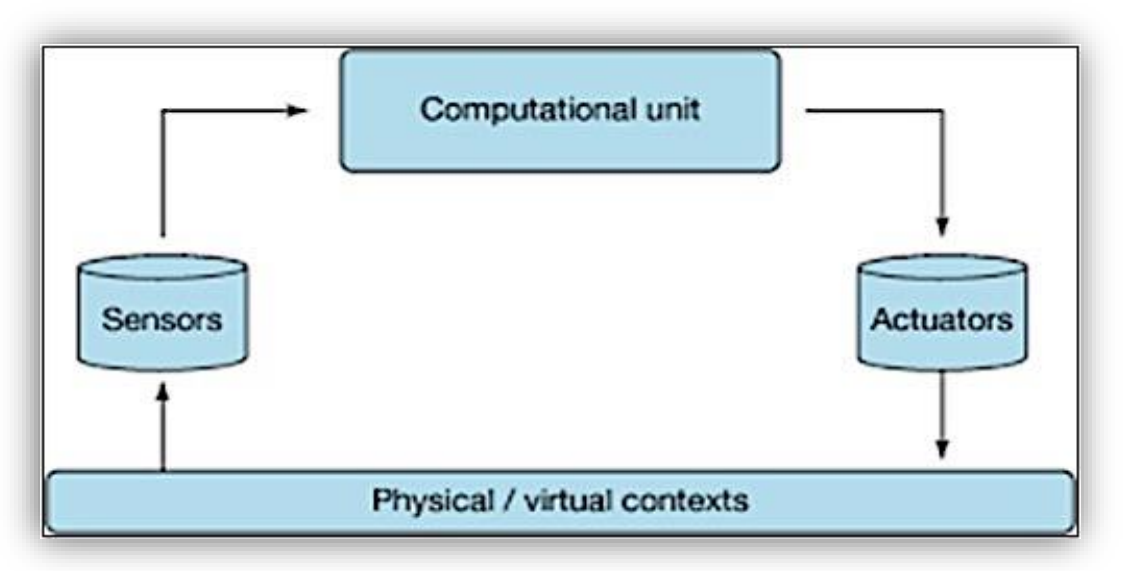

Fonte: IBM Developer (2015). 
Seu funcionamento permeia a alta capacidade de processamento de dados recebidos através dos sensores e, consequentemente, transmissão dos dados em forma de comando para os atuadores. Com base nos dados de retorno dos sensores, sua programação pondera as possíveis alternativas e atualizam essas informações em tempo real para os comandos estarem o mais preciso possível. Ainda, o CPS está conectado a central big-data que o atualiza das informações pertinentes e que funciona como um banco de dados, permitindo a análise e a comparação dos resultados com o banco de dados.

Importante frisar que o gerenciamento destes recursos se faz imprescindível para seu perfeito funcionamento e a inciativa privada vem se adequando com o passar dos anos. Com a existência de redes de integração de dados, as empresas da indústria 4.0 nunca estarão isoladas.

\subsubsection{Manufatura Aditiva}

Também chamada de Impressão 3D, hoje possui utilização na produção de protótipos físicos. $\mathrm{Na}$ indústria 4.0, ela é utilizada em grande escala para a produção de menores lotes de peças personalizadas, diminuindo altos custos de personalização e fabricação (Figura 5).

No processo de impressão 3D, as camadas de material são sobrepostas, concebendo o objeto modelado em um software dedicado, onde são elaborados o desenho e a escolha do tipo de material a ser utilizado na fabricação. Fazer uso da manufatura aditiva pode trazer inúmeros benefícios para as organizações, tais como velocidade de produção, baixo custo de produção unitária, liberdade de design e com níveis de complexidade elevado, alta customização e sustentabilidade.

Figura 5. Funcionamento de impressora 3D

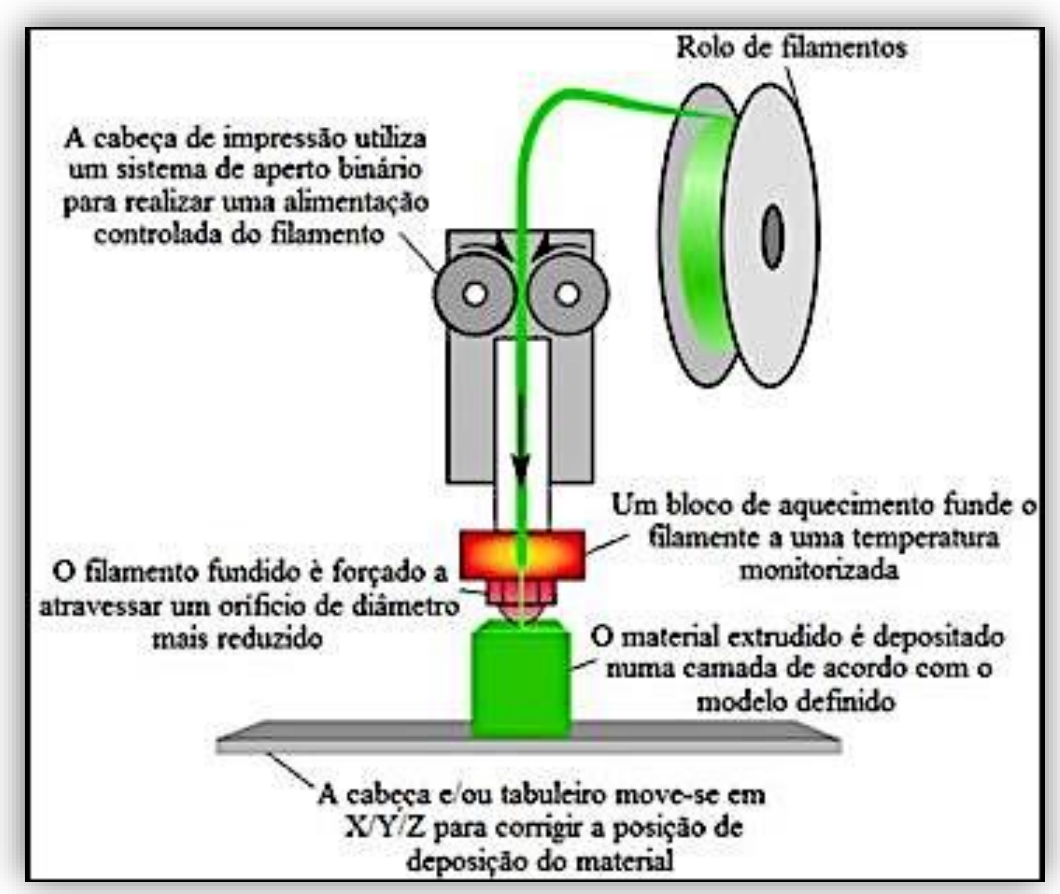

Fonte: Moreira (2016).

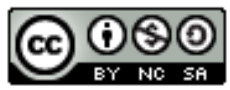




\subsubsection{Robô colaborativo}

Para indústrias mais autônomas, tais quais montadoras e envasadoras, a indústria 4.0 possui a tecnologia dos robôs colaborativos, que as desempenham de forma automática e/ou autônoma. De acordo com a organização Roboter In (2017), os robôs possuem a capacidade de interagir com o meio externo e tomar decisões de maneira independente, caso seja adaptado por meio das tecnologias, principalmente inteligência artificial de aprendizagem de máquina e IOT, combinadas as outras tecnologias, conforme necessidade.

Suas aplicações vão desde a checagem da linha de produção até a parada de produção inesperada pela detecção de falhas, pois possuem a autonomia capaz de ajustar-se a qualquer realidade. As empresas que investirem na autonomia de sua frota de robôs, pode ainda contar com a integração entre eles, máquinas e outros equipamentos. Essa integração permite também a economia e eliminação de outro pilar da indústria 4.0, a visão artificial.

O principal ganho a utilização desta ferramenta é a redução de custos com mão de obra humana qualificada e aumento da produção, tornando a organização mais competitiva.

\subsection{PROCESSO DE DESENVOLVIMENTO DE PRODUTO (PDP)}

Para que as organizações garantam vantagem competitiva com produtos inovadores, é necessário investir no aumento da capacidade de produção (flexibilidade entre qualidade e produtividade), além de um excelente desempenho no Processo de Desenvolvimento de Produto (PDP), obtido, em sua maioria, através de uma estratégia de desenvolvimento a longo prazo por uma equipe engajada e diversificada (Wheelwright \& Clark, 1993). Alguns fatores contribuem diretamente para o sucesso da organização e sua vantagem competitiva, muito importante para destaque e manutenção do mercado, como, a flexibilidade, confiabilidade da expedição e entrega, custo e velocidade produtiva (Slack et al., 2002).

O PDP tem como base a implementação de inovações em produtos no mercado gradualmente, considerando suas necessidades, níveis tecnológicos e atribuições organizacionais. Esses fatores, se combinados, possuem o objetivo de potencializar a evolução do processo produtivo baseando-se nas necessidades dos clientes (Mendes \& Toledo, 2003).

Para superar problemas de nível tecnológico, as empresas precisam utilizar métodos que poder demandar investimentos onerosos, mas que combinados geram bons resultados e eficiência na organização como capital humano qualificado ao que se destina, infraestrutura, reorganização e softwares modernos (Freitas et al., 2014).

Para Ferreira et al. (2014), é a empresa, segmento ou projeto a ser desenvolvido que determina a base tecnológica adequada para estruturar o desenvolvimento de produtos. Através do mapeamento de informações integrado as atividades e recursos, bem como a visão a cerda da área de conhecimento é organizado o modelo de PDP, cujo objetivo é gerar produtos de valor agregado para os clientes.

Segundo Rozenfeld et al. (2006), o principal modelo para definir o PDP é o MUR (Modelo Unificado de Referência), onde é dividido em três fases macro o processo de desenvolvimento de produto, sendo elas o Pré-desenvolvimento, Desenvolvimento e Pós-desenvolvimento. 
Citação (APA): Carvalho, F. L. S., de. \& Ferreira, J. L. (2022). Análise da maturidade do processo de desenvolvimento de produtos associados a indústria 4.0 no mercado capixaba através de pesquisa aplicada. Brazilian Journal of Production Engineering, 8(2), Edição Especial "Ciência na Prática", 01-21.

Nessas macros fases há também uma subdivisão em micro fases, atividades e tarefas fundamentais para o sucesso do desenvolvimento de produto.

Salgado et al. (2010), após realizar um levantamento sobre os modelos de PDP existentes, concluiu que embora haja um roteiro de desenvolvimento, fases, tarefas e atividades préestabelecidas, as mesmas se encontram com várias indicações distintas, fundamentadas pelo grau de generalização do PDP. Ou seja, ainda que haja um modelo, as organizações devem escolher o melhor modelo conforme suas atividades. Para auxiliar o PDP, existem variadas técnicas e podem ser aplicadas em conjunto, angariando bons resultados para as organizações, principalmente no fator qualidade, como o CAD (Computer Aided Design), Matriz Morfológica, FMEA (Failure Mode And Effect Analysis), dentre outros (Toledo et al., 2008).

Badin (2005), considera ganho produtivo envolver os fornecedores em todas as etapas do processo de desenvolvimento de produto. Esse envolvimento ajuda e redução de riscos eminentes nas etapas compostas no PDP e essa relação entre os fornecedores e área tecnológica tem como base mitigar as falhas e garantir a qualidade esperada pelo cliente.

\subsection{MODELO DE REFERENCIA ESTRUTURADO}

Como base para desenvolvimento da pesquisa, foi utilizado o modelo de referência estruturado para gestão do processo de desenvolvimento de produtos proposto por Rozenfeld et al. (2006) (Figura 6).

Pré-desenvolvimento: Também chamada de planejamento do produto, é especificado qual produto será desenvolvido, através do escopo do projeto, capacidade de risco, monitoramento e definição de planos de negócios. Entretanto, anterior a esta fase há o planejamento estratégico verificando o nível de sucesso que o produto poderá alcançar.

$\checkmark$ Desenvolvimento: neste ponto o número de atividades se eleva consideravelmente e pode ser subdividida em cinco partes.

1. Projeto Informacional, são coletadas todas as informações que o cliente ou mercado pretende.

2. Projeto Conceitual, cuja funcionalidade é a adaptação das informações anteriores as definições do produto.

3. Projeto Preliminar são avaliados o conceito e a estrutura funcional do produto.

4. Projeto Detalhado tem a finalidade de desenvolver e finalizar as suas especificações, dando sequência a fase anterior. Após a realização desta etapa, o desenvolvimento se encaminha para a produção do produto e próximas fases. Com a conclusão das especificações, protótipo final e outros requisitos obtidos a partir do Projeto Detalhado, na etapa de Preparação da Produção serão de fatos preparados os processos de produção do objeto.

5. Lançamento do Produto, cuja fase é a última da macro fase de desenvolvimento, com as especificações do produto e do processo produtivo e manutenção, é definido o processo de ventas, logística, assistência técnica e atendimento ao cliente.

$\checkmark$ Pós-desenvolvimento: é a última parte do processo, uma vez que é planejado como será feito o acompanhamento e a retirada do mercado, esclarecidos as equipes e os meios para as modificações de engenharia que visam a correção de potenciais falhas e/ou melhorias, requeridas pelo consumidor. 
Citação (APA): Carvalho, F. L. S., de. \& Ferreira, J. L. (2022). Análise da maturidade do processo de desenvolvimento de produtos associados a indústria 4.0 no mercado capixaba através de pesquisa aplicada. Brazilian Journal of Production Engineering, 8(2), Edição Especial "Ciência na Prática", 01-21.

Figura 6. Etapas do processo de desenvolvimento de produtos.

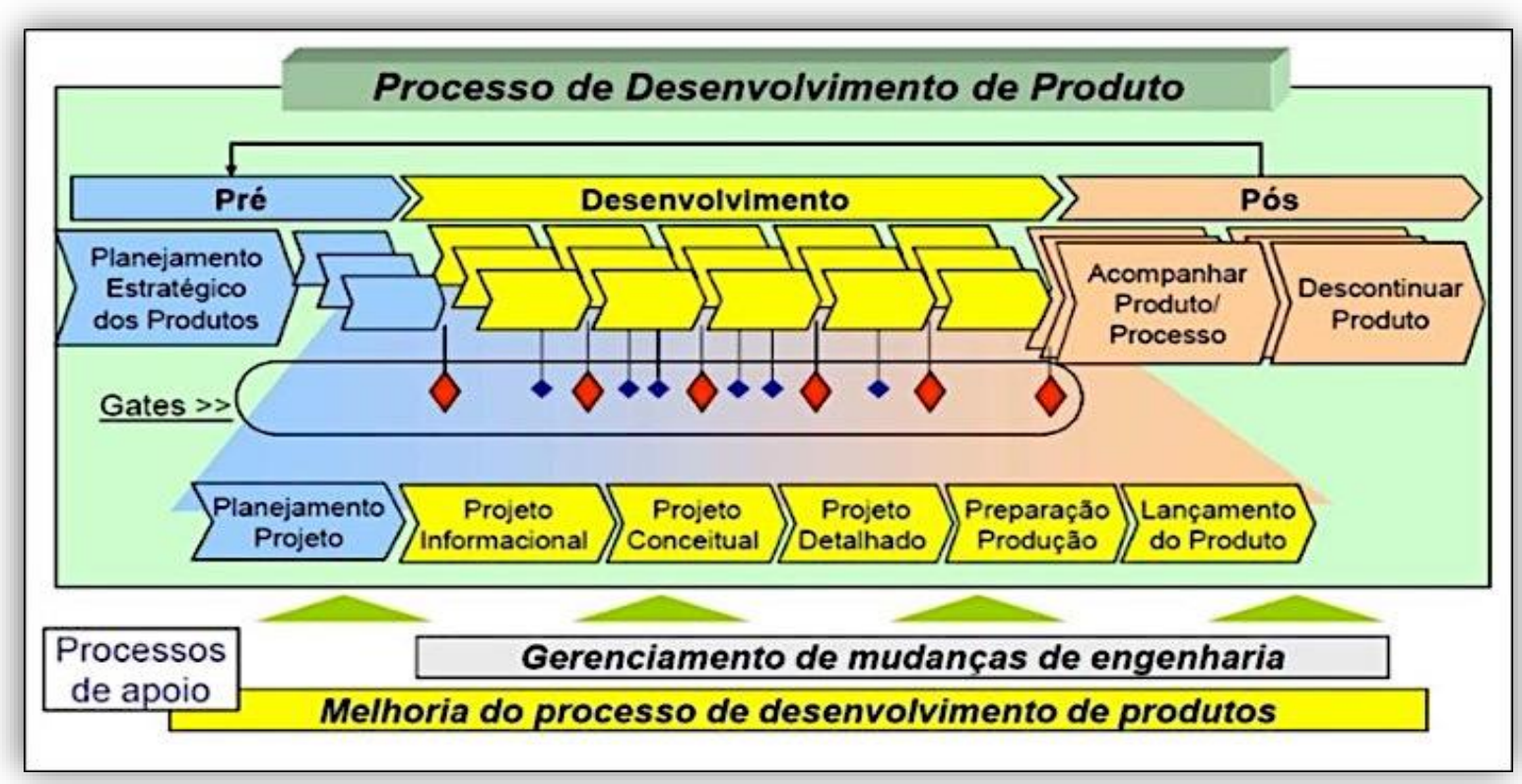

Fonte: Adaptado de Rozenfeld et al., (2006).

\section{METODOLOGIA}

Uma vez que este desenvolvimento envolve a avaliação do atual estado de maturidade do PDP em empresas capixabas de diferentes portes, foi necessário a elaboração de uma metodologia capaz de avaliar cada uma delas. Para o desenvolvimento da mesma, realizou-se uma revisão das metodologias existentes na literatura visando adaptar o conhecimento a realidade da industrial capixaba.

Desta forma, do ponto de vista dos objetivos e da forma de abordagem do problema, pode-se classificar esta pesquisa com sendo de caráter explicativo e quali-quantitativa, uma vez que o mesmo busca diagnosticar um segmento industrial e interpretar relações entre as variáveis do estudo e o processo de desenvolvimento do produto.

Todas as informações coletadas das literaturas serviu de base para construção de um questionário aplicado por meio de entrevista direta e/ou indireta (e-mail, questionário eletrônico) a 68 empresas do estado do Espírito Santo, previamente selecionadas e pertencentes a nove segmentos, sendo eles: comercio varejista, prestadores de serviços, fabricação de produtos alimentícios, indústria extrativa, metalurgia, indústria geral e fabricação de papel, com faturamento correspondente a pequena empresa até empresa de grande porte. Neste questionário, foram levantados: o grau de padronização dos produtos capixabas, as ferramentas utilizadas, o lead time entre a produção e a disposição do produto no mercado e o papel do engenheiro de produção nesse segmento. Logo, a partir dessas informações, se pôde verificar a acerca do processo de desenvolvimento de produto e a utilização de ferramentas específicas para o processo que foram mostradas nos resultados.

A base inicial de industriais será composta pelos dados do sistema FINDES (2019) na qual são apresentados as 200 Maiores Empresas no Espírito Santo no ano de 2019. Além destas empresas

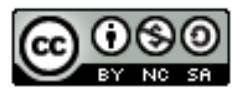


poderão ser incluídas as empresas de pequeno porte não contidas nesta base específica. As empresas foram divididas em indústrias de pequeno, médio e grande porte de acordo com sua receita bruta e volume de produção.

Para aplicação dos questionários e levantamento das informações acerca do processo de desenvolvimento do produto foram utilizados os meios de comunicação disponibilizados pelas indústrias como contato inicial. A partir deste contato foi proposto as empresas a realização de entrevistas com visita as instalações industriais quando possível e/ou envio de questionários por meio eletrônico ou e-mail. Mais de um questionário foi aplicado a funcionários diferentes em uma mesma empresa, para mensurar a interpretação dos mesmos. Este foi elaborado na forma de respostas fechadas prioritariamente visando a rapidez e facilidade de resposta por parte do entrevistado e a posterior categorização das respostas para análise. Onde os nomes de todas as empresas serão mantidos em sigilo, utilizando para suas identificações, quando necessário, códigos conforme seu porte (exemplo: P1 - empresa de pequeno porte 1).

Todas informações levantadas foram tratadas estatisticamente no Microsoft Excel visando relacionar as práticas de desenvolvimento do produto com os resultados encontrados com as empresas numa avaliação global e pelo porte das indústrias.

\section{RESULTADOS E DISCUSSÃO}

O presente artigo teve como embasamento metodológico a construção de um questionário aplicado por meio de entrevista através da revisão das metodologias existentes na literatura visando adaptar o conhecimento a realidade da industrial capixaba. Ao todo, foram captadas respostas de 68 empresas capixabas, de diferentes portes e segmentos.

\subsection{PROCESSO DE DESENVOLVIMENTO DE PRODUTO - PDP}

No que tange o Processo de Desenvolvimento de Produto, constata-se que 79\% das empresas entrevistadas possui uma equipe dedicada a criação de novos produtos. Essa informação é de grande valia, visto que há um investimento e valorização na equipe dedicada a estudo de mercado e desenvolvimento do produto, ainda que intangível. Diante disso, pudemos avaliar também os profissionais envolvidos no PDP e sua relevância dentro dessas empresas. Conforme o gráfico 1, considerando as notas de 1 a 5 , sendo sem importância a extremamente importante no PDP, para as empresas consultadas, as áreas mais relevantes para o PDP são Qualidade e Financeiro, respectivamente. A áreas de Engenharia de Produto e Processos vem logo em seguida, demonstrando que o mercado se preocupa com a qualidade do produto ofertado, mas está diretamente ligado ao retorno financeiro do mesmo, podendo concluir que em dado momento a qualidade pode cair para que a saúde financeira da empresa se mantenha. 

Especial "Ciência na Prática", 01-21.

Gráfico 1. Relevância das áreas no PDP capixaba

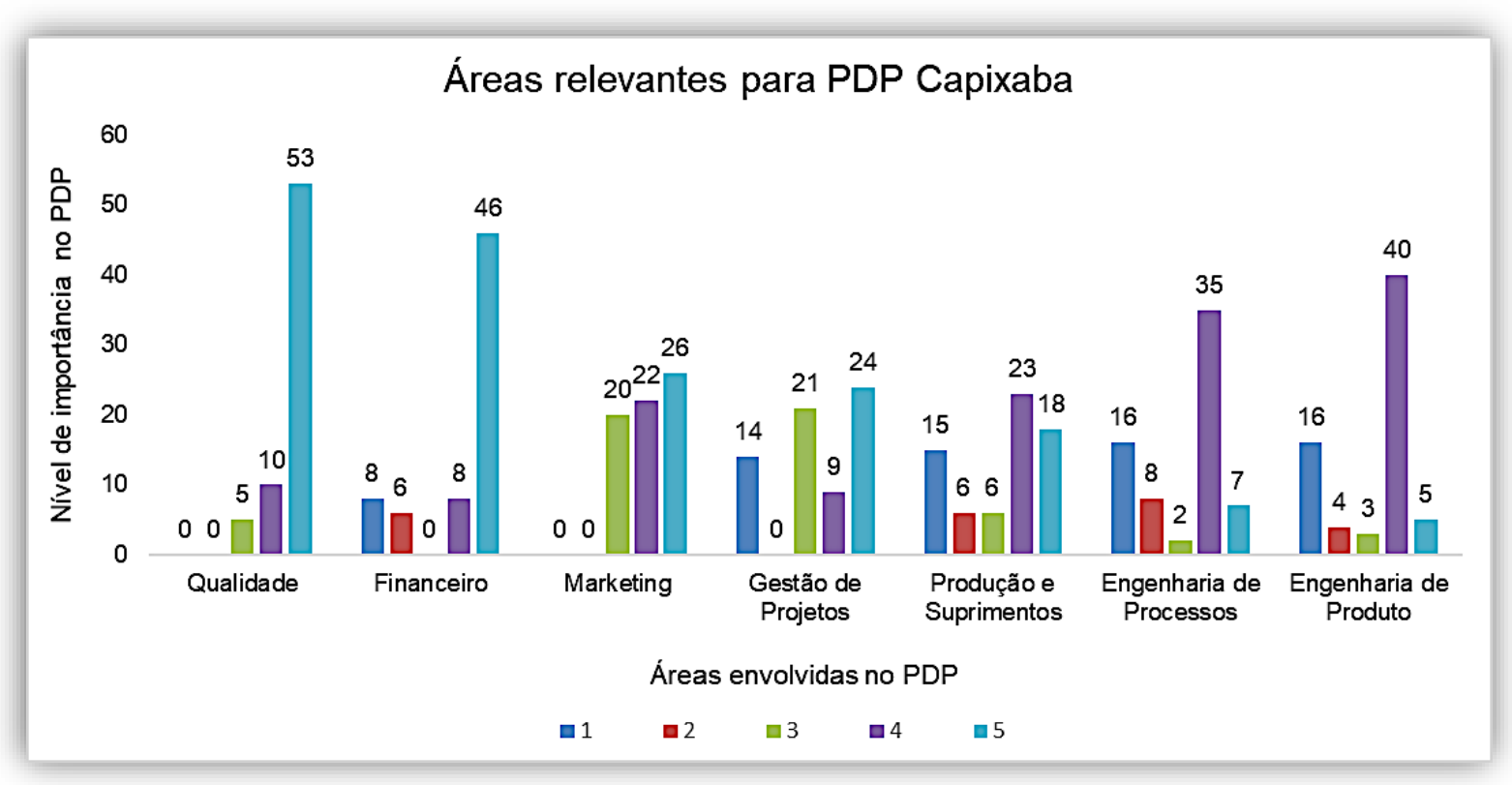

Fonte: Autores (2021).

Para alcançar o lançamento de novos produtos, conforme o gráfico 2, 46\% das empresas utilizam, ainda, a observação direta. Mas apenas 15\% das empresas utilizam a ferramenta CRM (Customer Relationship Management, ou, gestão de relacionamento com o cliente - é um software que permite registrar e organizar todos pontos de um contato que um consumidor tem com o vendedor de uma empresa).

Gráfico 2. Metodologia Utilizada para Lançamento de Novos Produtos

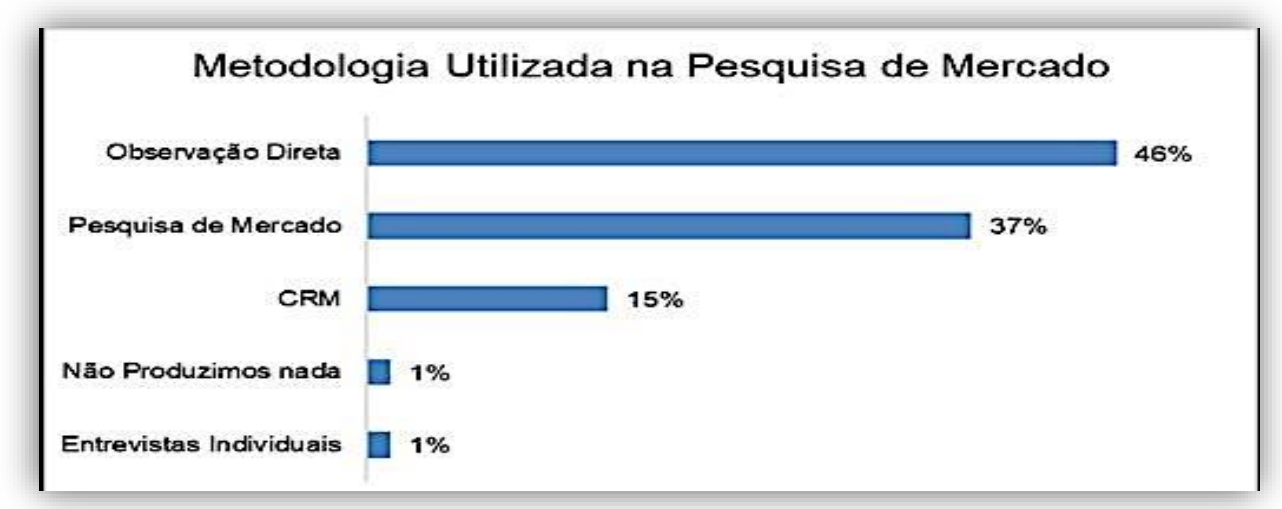

Fonte: Autores (2021).

Quando citamos o processo de desenvolvimento de produto é sugestivo a padronização e uso de softwares para o planejamento e até produção do mesmo. Diante disso, a pesquisa nos traz que 38\% das empresas consultadas possuem total ausência de padronização e tampouco utilizam softwares para o desenvolvimento dos seus produtos, $50 \%$ fazem uso de softwares e tem seus produtos padronizados e $12 \%$ utilizam softwares, mas não possuem em seu portfólio produtos padronizados. Esses números impressionam, visto que um PDP sistematizado e documentado permite que as particularidades de cada projeto e equipe de desenvolvimento

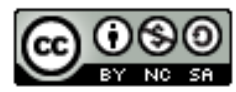


sejam atendidas e, ao mesmo tempo, garante-se a utilização das melhores práticas de projeto e um linguajar padronizado e único para toda a corporação.

Já nas ferramentas utilizadas para o PDP, $31 \%$ fazem uso, exclusivamente, da Matriz Morfológica (MM). Quando analisamos as ferramentas combinadas, essa estimativa tende a aumentar, visto que a MM aparece junto ao QFD (Quality Function Deployment Desdobramento da Função Qualidade), FMEA (Failure Mode and Effects Analysis - Análise dos Modos de Falha e Seus Efeitos) e CAD (computer-aided design - Projeto Assistido por Computador). Mas impressiona por, $21 \%$ das empresas pesquisadas não fazerem uso de quaisquer ferramentas existentes para desenvolvimento (Gráfico 3).

Gráfico 3. Ferramentas Utilizadas para o PDP

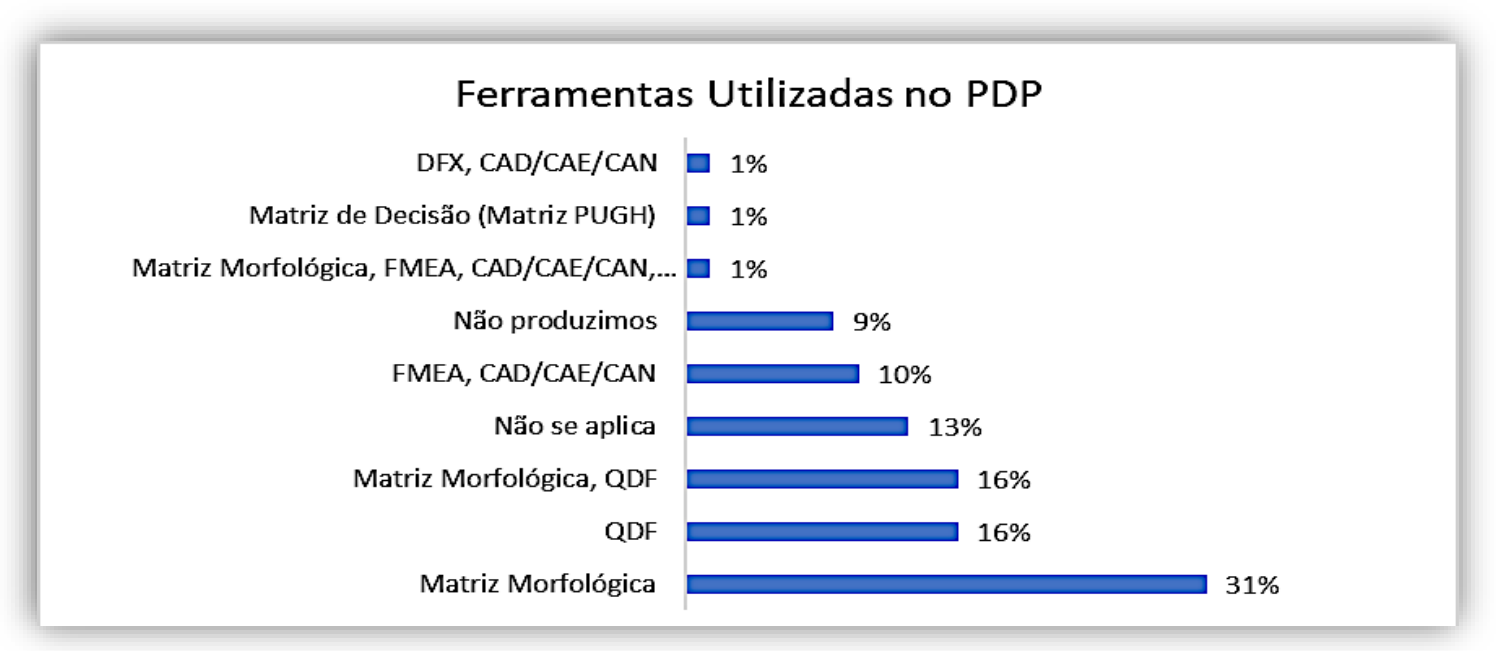

Fonte: Autores (2021).

\subsection{INDÚSTRIA 4.0}

No que se refere a indústria 4.0 e seus pilares tecnológicos descritos cada um a seguir, pode-se perceber que $90 \%$ das empresas participantes são capazes de detectar entrada e saída dos produtos no estoque virtualmente, porém apenas $51 \%$ dessas empresas acessam essas e outras informações remotamente (Gráfico 4).

Gráfico 4. Análise entre as variáveis de controle de estoque e monitoramento remoto

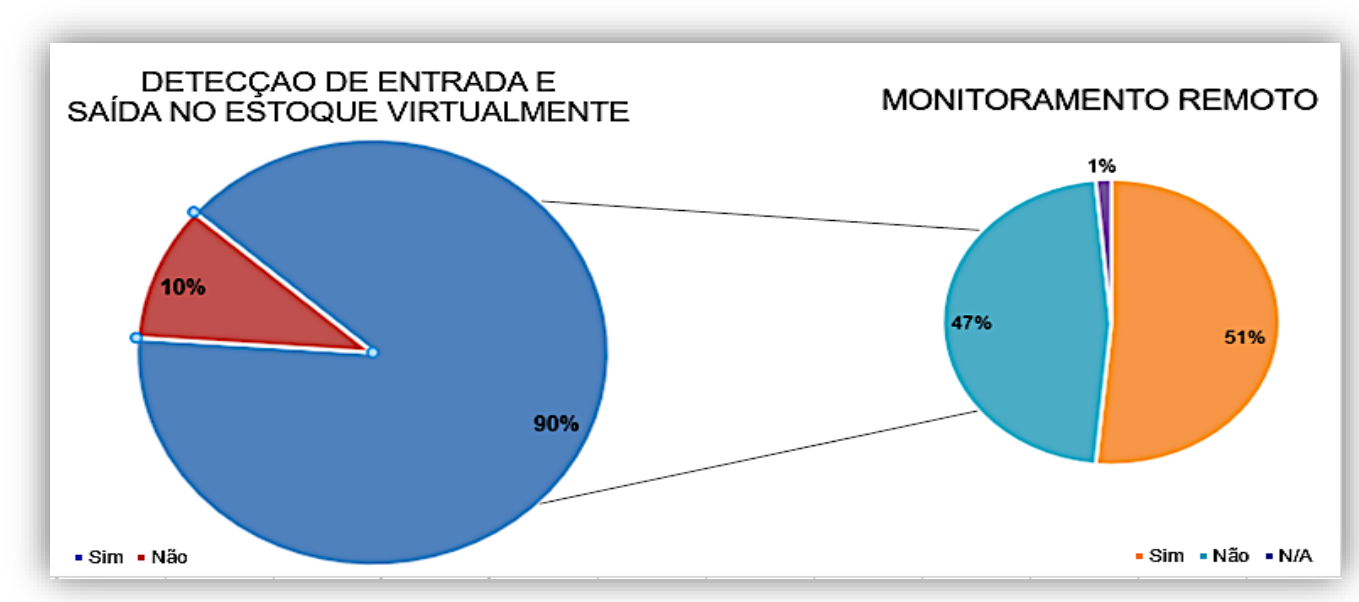

Fonte: Autores (2021).

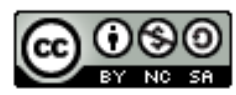


Diante dos resultados relacionados a qualidade do produto na linha de produção, foi constatado que o checkout de qualidade é possível para $38 \%$ das empresas em qualquer etapa da cadeia produtiva, ou seja, para avaliação de matéria prima, usabilidade e padrões, garantindo assim a qualidade esperada durante o estudo de viabilidade do produto (Gráfico 5).

Gráfico 5. Inspeção de qualidade na linha de produção

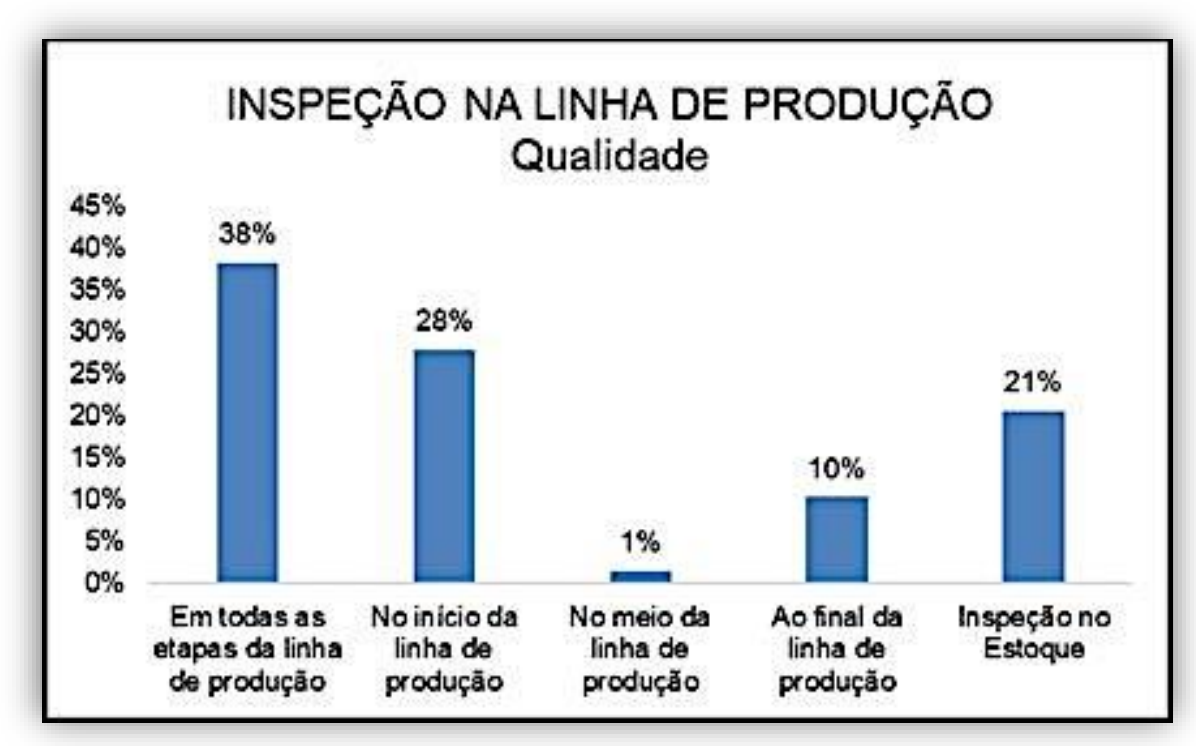

Fonte: Autores (2021).

Enquanto para checkout de problemas relacionados a portfólio, tipagem e peso só é possível no início da linha de produção para $43 \%$ das empresas, conforme o Gráfico 6. Esse resultado nos traz a constatação que o produto ainda tem sua qualidade testada e/ou certificada com o produto em estoque ou chegando ao cliente, elevando o custo logístico, o custo de fabricação e perda de homem/hora.

Gráfico 6. Inspeção de problemas na linha de produção

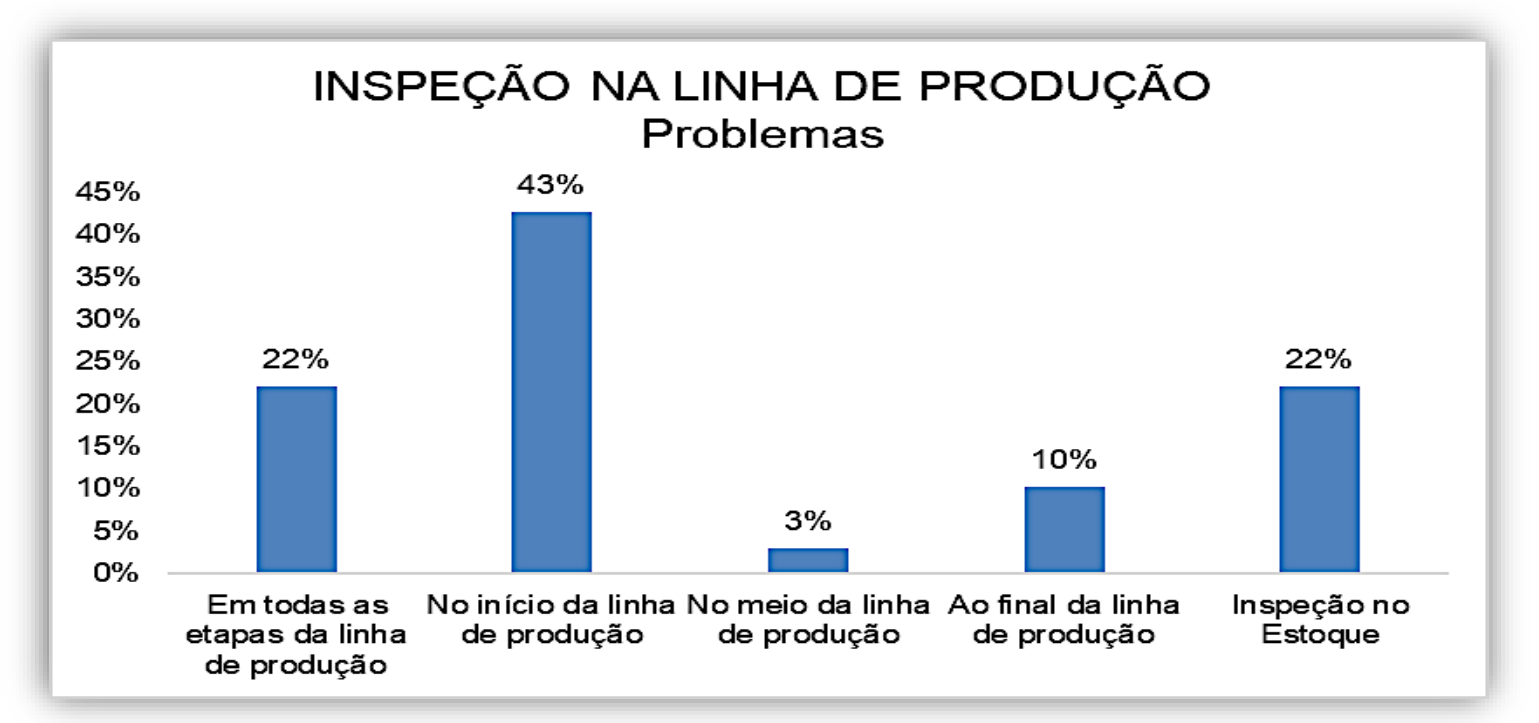

Fonte: Autores (2021). 
Cerca de $22 \%$ não inspeciona o produto em nenhuma etapa, somente quando o produto é estocado e por amostragem. O controle amostral embora não interfira no processo produtivo, precisa ser avaliada se é a melhor escolha, pois se uma amostra é aprovada então todo o lote será aprovado, caso contrário todo o lote será reprovado. Diante disso o custo de reprocessamento e o risco de satisfação do cliente precisam ser considerados.

A tomada de decisões, feita pelo sistema cyber-físico de acordo com as necessidades da produção em tempo real só é possível em $49 \%$ das empresas consultadas e cerca de $36 \%$ das mesmas não fazem uso de qualquer sistema em nuvem. Afim de garantir a segurança de seus processos de desenvolvimento e produção, bem como a simulação de processos e tomada de decisões, se faz necessário o backup e a simulação de operação. Esses elementos são requisitos fundamentais na indústria 4.0, uma vez que fornece recursos, armazenamento e processamento de dados em escala. Entre as vantagens da computação em nuvem destaca-se a flexibilidade e a agilidade no fornecimento dos recursos necessários para a tomada de decisão das empresas que aderiram ao novo modelo industrial. Diante disso 50\% das empresas possuem backup dos seus dados, protótipos e operações e apenas 35\% podem simular e rastrear na nuvem. Em tempo, cerca de $19 \%$ das empresas participantes arriscam-se no mercado sem rastreabilidade ou backup (Grafico 7).

Gráfico 7. Análise nuvem de dados e simulação

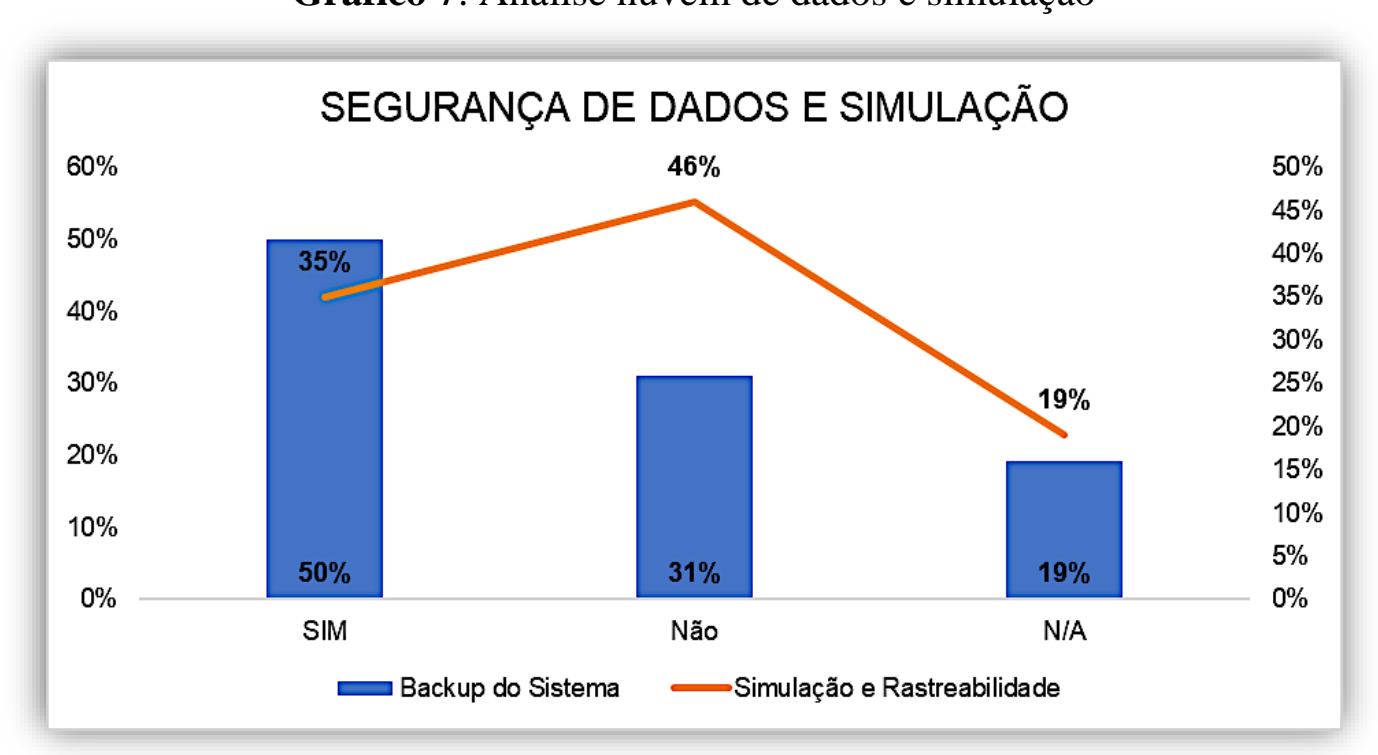

Fonte: Autores (2021).

Em se tratando de logística reversa, conforme o Gráfico 8, somente $29 \%$ das organizações possuem essa operação. Segundo dados do Instituto Brasileiro de Desenvolvimento Sustentável (Relatório de Sustentabilidade do Instituto Aço Brasil), a indústria siderúrgica brasileira é responsável por $2,1 \%$ da produção mundial de aço, ocupando a $8^{\mathrm{a}}$ posição no ranking. Aproximadamente $30 \%$ dos produtos são feitos de sucata, o que indica que há mercado para reaproveitar os excedentes da siderurgia. Considerando isso, de acordo com a pesquisa, das empresas que não fazem a logística reversa, $77 \%$ tratam seus resíduos totalmente ou parcialmente e somente $9 \%$ não tem qualquer tratamento das sobras e resíduos.

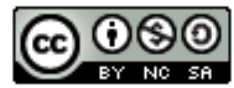


Citação (APA): Carvalho, F. L. S., de. \& Ferreira, J. L. (2022). Análise da maturidade do processo de desenvolvimento de produtos associados a indústria 4.0 no mercado capixaba através de pesquisa aplicada. Brazilian Journal of Production Engineering, 8(2), Edição Especial "Ciência na Prática", 01-21.

Gráfico 8. Análise das variáveis de reversa e aproveitamento de resíduos na cadeia de produção

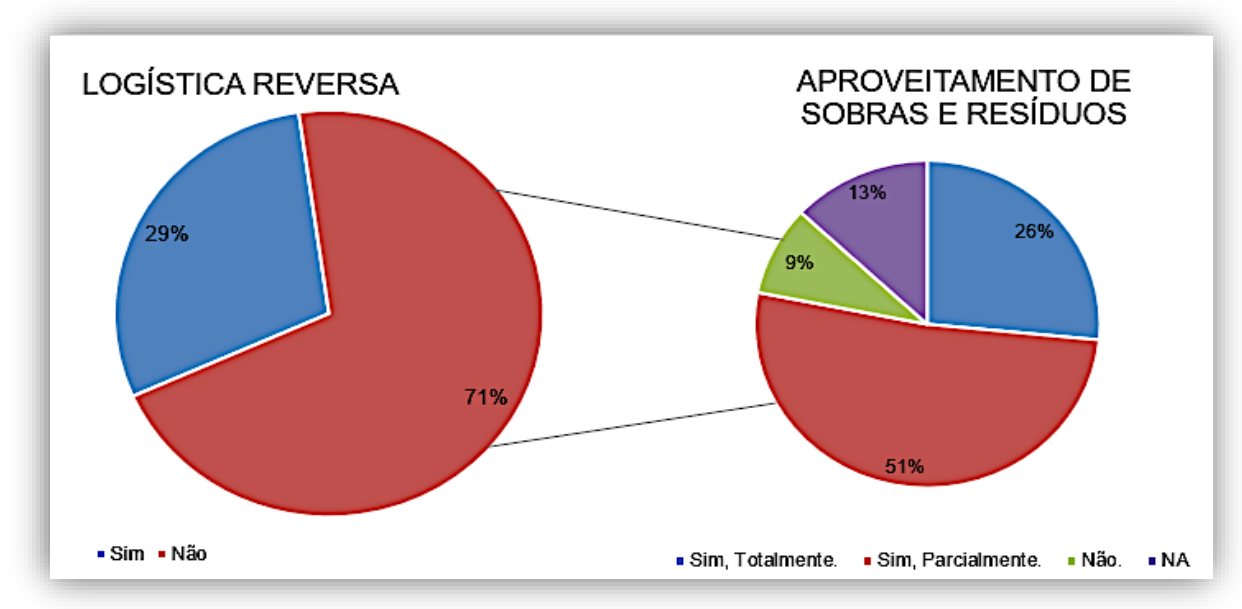

Fonte: Autores (2021).

\section{CONCLUSÃO}

Quanto as conclusões deste artigo, valida-se a metodologia aplicada, visto que através da mesma foi possível constatar que o mercado capixaba ainda está imaturo no que tange o PDP. O processo de desenvolvimento de produto está muito aquém da indústria 4.0, conforme seus objetivos e resultados, mostrou-se a ideia de que a maioria das empresas capixabas ainda não conhecem os benefícios desta era e tampouco investe em profissionais adequados para execução do mesmo.

Diante disso, foi possível constatar que o Engenheiro de Produção ocupa cerca de $17 \%$ das áreas responsáveis pelo desenvolvimento do produto, sendo $66 \%$ das áreas ocupadas pelos profissionais de Marketing e Qualidade (Quadro 2).

Quadro 2. Áreas responsáveis pelas principais áreas do PDP

\begin{tabular}{|c|c|}
\hline \multicolumn{2}{|c|}{ PRINCIPAIS ÁREAS DO PDP } \\
\hline $\begin{array}{c}\text { Definir escopo e } \\
\text { planejamento estratégico }\end{array}$ & Engenheiro de Processo \\
\hline $\begin{array}{l}\text { Modelagem funcional e } \\
\text { aplicação das ferramentas do PDP }\end{array}$ & Engenheiro de Processo \\
\hline $\begin{array}{l}\text { Processo de aprovação entre } \\
\text { etapas de desenvolvimento (qates) }\end{array}$ & Engenheiro de Produção \\
\hline Análise dos riscos & $\begin{array}{c}\text { Engenheiro de Produção/ } \\
\text { Gestão de Programas e Custos }\end{array}$ \\
\hline Comunicação com a alta diretoria & Gestão de Programas e Custos \\
\hline Negociação com os fornecedores & Gestão de Programas e Custos \\
\hline Compra de recursos & Gestão de Programas e Custos \\
\hline Analisar portifólio & Marketing e Qualidade \\
\hline Estudo de viabilidade & Marketing e Qualidade \\
\hline $\begin{array}{l}\text { Produção de lote piloto e } \\
\text { homoloqacão do processo }\end{array}$ & Marketing e Qualidade \\
\hline Liberação da produção & Marketing e Qualidade \\
\hline Estratégia para lançamento do produto & Marketing e Qualidade \\
\hline
\end{tabular}

Fonte: Autores (2021). 
Citação (APA): Carvalho, F. L. S., de. \& Ferreira, J. L. (2022). Análise da maturidade do processo de desenvolvimento de produtos associados a indústria 4.0 no mercado capixaba através de pesquisa aplicada. Brazilian Journal of Production Engineering, 8(2), Edição Especial "Ciência na Prática", 01-21.

Vale ressaltar que a Engenharia de Produção não é somente gestão de informações e análise de resultados, também é plenamente capaz, e o profissional mais indicado, para o desenvolvimento de produto, otimização, redução de custo, melhoria contínua e afins.

Portanto, buscou-se neste trabalho a apresentação da aplicação da avaliação a pelo menos a uma indústria de cada porte (pequeno, médio, grande), pois com todas as informações levantadas foi possível construir uma base de dados robusta capaz de dimensionar a necessidade de desenvolvimento de um programa de capacitação voltado para as indústrias de todos os portes do estado do Espírito Santo, através de consultorias, bem como a aplicação da proposta de fábrica inteligente e seu aproveitamento.

Para desenvolvimento de resultados mais assertivos e completos, sugerisse um estudo de viabilidade financeira visando assim a criação ou desenvolvimento de uma empresa mais preparada quanto a sistema indústria 4.0 (FINDES, SEBRAE, demais órgãos financeiros) ou ainda, visando o aprimoramento de uma empresa já existente no que tange a uma melhor adequação a indústria 4.0, obtendo assim grandes resultados de produção, qualidade e liquidez financeira.

\section{REFERÊNCIAS}

Alliprandini, D. H. \& Scalice, R. K. (2006). Gestão de desenvolvimento de produto: uma referência para a melhoria do processo. São Paulo: Saraiva. 542p.

Badin, N. T. (2005). Modelo de referência para o processo de desenvolvimento de produtos integrando fornecedores e baseado nos conceitos de engenharia simultânea, custeio-alvo e empresa virtual. Dissertação (Programa de Pós-Graduação em Engenharia de Produção) Centro Tecnológico. Universidade Federal de Santa Catarina, Santa Catarina.

Baxter, M. (1998). Projeto do produto: guia prático para o design de novos produtos. 2.ed. São Paulo: Edgard Blucher Ltda. 342p.

Cobbos, M. (2018). O que é computação em nuvem e como ela está inserida na indústria. Recuperado de https://www.pollux.com.br/blog/o-que-e-computacao-em-nuvem-e-em-queprocessos-ela-esta-naindustria/\#: :text=A\%20computa\%C3\%A7\%C3\%A3o\%20em\%20nuvem\%20elimina, armaze namento $\% 20 \mathrm{e} \% 20$ processamento $\% 2 \mathrm{C} \% 20 \mathrm{entre} \% 20 \mathrm{outros}$

Freitas, F. L., Ferreira, M. P., Matsuo, T. K., Forcellini, F. A., \& Orofino, M. A. R. (2014). Processo de desenvolvimento de produto: aplicação em um Projeto de P\&D dentro do programa ANEEL. XXIV Seminário Nacional de Parques Tecnológicos e Incubadoras de empresas; Belém, Pará.

IEL-ES. (2019). 200 Maiores e melhores empresas do Espírito Santo. Recuperado de https://issuu.com/iel-docs/docs/anu_rio_iel_200_maiores_2019

Instituto Jones dos Santos Neves. (2019). Conjuntura Econômica. Recuperado de http://www.ijsn.es.gov.br/indicadores-n/conjuntura-economica

Instituto Jones dos Santos Neves. (2019). PIB trimestral. Recuperado de http://www.ijsn.es.gov.br/artigos/5515-pib-trimestral-3-trimestre-de-2019

Instituto Jones dos Santos Neves. (2019). PIB trimestral. Recuperado de http://www.ijsn.es.gov.br/artigos/5580-pib-trimestral-4-trimestre-de-2019 
Citação (APA): Carvalho, F. L. S., de. \& Ferreira, J. L. (2022). Análise da maturidade do processo de desenvolvimento de produtos associados a indústria 4.0 no mercado capixaba através de pesquisa aplicada. Brazilian Journal of Production Engineering, 8(2), Edição Especial "Ciência na Prática", 01-21.

Jugend, D. (2006). Desenvolvimento de produtos em pequenas e médias empresas de base tecnológica: práticas de gestão do setor de automação de controle de processos. Dissertação de mestrado (Mestrando em Engenharia de Produção). Universidade Federal de São Carlos, São Paulo. Recuperado de http://www.gepeq.dep.ufscar.br/arquivos/DissDanielJugend.pdf

Leone, G. S. G. \& Leone, R. J. G. (2007). Os 12 mandamentos da gestão de custos. FGV.

Magnus, T. (2018). Indústria 4.0 no Brasil: quais os impactos para as empresas. Recuperado de https://www.totvs.com/blog/gestao-industrial/impactos-da-industria40/\#: :text=Dessa\%20forma\%2C\%20estipula\%2Dse\%20que,de\%20sistemas\%20e\%20sensor es\%20inteligentes

Magrini, E. (2018). Internet das coisas. Rio de Janeiro. FGV Editora

Mark, S. \& Felix, H. (2018). The fourth industrial revolution: Responding to the Impact of Artificial Intelligence on Business. Palgrave Macmillan.

Mendes, G. H. S. \& Toledo, J. C. (2003). Uma Visão dos Principais Arranjos Organizacionais Aplicados ao Desenvolvimento de Produto. IV Congr. Bras. Gestão e Desenv. de Produtos Gramado, RS, Brasil, 6 a 8 de out de 2003.

Moreira, R. M. D. (2016). Concepção de um sistema de medição sem contacto da temperatura do polímero à saída do bico de uma impressora 3D FDM. Faculdade de Engenharia Universidade do Porto. 2016. 99 p. Dissertação (Mestrado) - Engenharia de Automação.

Moura, M. C. \& Nascimento, L. M. (2018). Excelência Operacional: Indústria 4.0 e simulação de processos produtivos: como os gêmeos digitais podem ajudar na busca da excelência operacional? Recuperado de http://www.excelenciaoperacional.blog.br/2018/08/31/industria4-0-e-simulacao-de-processos-produtivos-como-os-gemeos-digitais-podem-ajudar-na-buscada-excelencia-operacional/

QS Consultoria. (2017). Sistema para rastreabilidade de produto - dicas parra escolher um para sua indústria. Recuperado de https://qsconsultoria.com.br/sistema-rastreabilidadeproduto-dicas-para-escolher-industria/

Ramos, R. O (2017). Estatístico: Evento: Big Data Revolution, Recuperado de https://oestatistico.com.br/evento-big-data-revolution/

Roboter I. (2017). O que é um robô colaborativo? Recuperado de http://roboterin.com.br/oque-e-um-robo-

colaborativo/\#: :text=Esse\%20tipo\%20de\%20recurso\%20colaborativo,em\%20seu\%20espa\% C3\%A7o\%20de\%20trabalho.\&text=Desta\%20forma\%2C\%20a\%20pessoa\%20pode,estar\%20 no\%20espa\%C3\%A7o\%20do\%20rob\%C3\%B4

Rocha, A. \& Vendrametto, O. (2016). Seleção de indicadores de eficiência da competitividade industrial Brasileira. São Paulo: Bluscher.

Rozenfeld, H., et al., (2006). Gestão de desenvolvimento de produtos: uma referência para a melhoria do processo. São Paulo: Saraiva.

RTI Automação. (2018). A importância do Sistema de Visão Artificial na Automação Industrial. Recuperado de https://www.rtiautomacao.com.br/importancia-do-sistema-de-visaoartificial-na-automacao-

industrial/\#: : text=Portanto $\% 2 \mathrm{C} \% 20 \mathrm{comprovadamente} \% 2 \mathrm{C} \% 20 \mathrm{o} \% 20 \mathrm{uso} \% 20 \mathrm{da}, \mathrm{e} \% 20 \mathrm{efici} \%$ C3\%AAncia\%20nas\%20etapas\%20produtivas

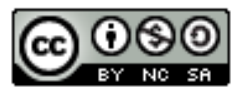

Esta obra está licenciada com uma Licença Creative Commons Atribuição-Não Comercial-Compartilha Igual 4.0 Internacional. Brazilian Journal of Production Engineering, São Mateus, Editora UFES/CEUNES/DETEC. 

Especial "Ciência na Prática", 01-21.

Sacomano, J. B. \& Sátyro, W. C. (2018). Indústria 4.0: conceitos fundamentais. São Paulo: Blusher.

Salgado, E. G., Salomon, V. A. P., Mello, C. H. P., Fass, F. D. M., \& Xavier, A. F. (2016). Modelo de referência para desenvolvimento de produtos: Classificação, análise e sugestões para pesquisas futuras. Revista Produção Online, 10(4), 886-911. https://doi.org/10.14488/16761901.v10i4.520

Silva, C. E. S., da. (2001). Método para avaliação do desempenho do processo de desenvolvimento de produtos. 188f; Tese (Doutorado em Engenharia de Produção); Universidade Federal de Santa Catarina; Florianópolis; 2001, Recuperado de https://repositorio.ufsc.br/bitstream/handle/123456789/80429/181648.pdf?sequen

Silveira, C. B. (2017). O que é indústria 4.0 e como ela vai impactar o mundo. Recuperado de https://www.muraki.org.br/o-que-e-industria-4-0-e-como-ela-vai-impactar-omundo/\#: : text=\%C3\%89\%20um\%20conceito\%20de\%20ind\%C3\%BAstria, aplicadas\%20ao s\%20processos\%20de\%20manufatura

Sistema Findes.(2016). Maiores empresas no Espírito Santo serão conhecidas em evento especial, Recuperado de http://www.sistemafindes.org.br/2016/10/10/200-maiores-empresasno-espirito-santo-serao-conhecidas-em-evento-especial/

Slack, N., Chambers, S. \& Johnston, R. (2002). Administração da Produção. 2. ed. São Paulo: Atlas.

Souza, J. (2018). Oportunidades fiscais e tributárias na Indústria 4.0. Recuperado de https://portogente.com.br/noticias/opiniao/103114-as-oportunidades-fiscais-e-tributarias-naindustria-4-0

Teles, J. (2018). Indústria 4.0 - Tudo que você precisa saber sobre a Quarta Revolução Industrial. Recuperado de https://engeteles.com.br/industria-4-0/

Toledo, J. C., et al., (2008). Práticas de gestão no desenvolvimento de produtos em empresas de autopeças. Produção, 18(2), 405-422.

Wheelwright, S. C., \& Clark, K. B. (1993). Managing new product and process development: text and cases. New York: The Free Press.

Wheelwright, S. C. \& Clark, K. B. (1993). Managing new product and process development text and cases. New York: HBS.

Winter, J. E. (2016). Aware technologies: Sistemas Ciber-físicos: A Nova Revolução. Recuperado de https://www.eaware.com.br/sistemas-ciber-fisicos-a-nova-revolucao/ 